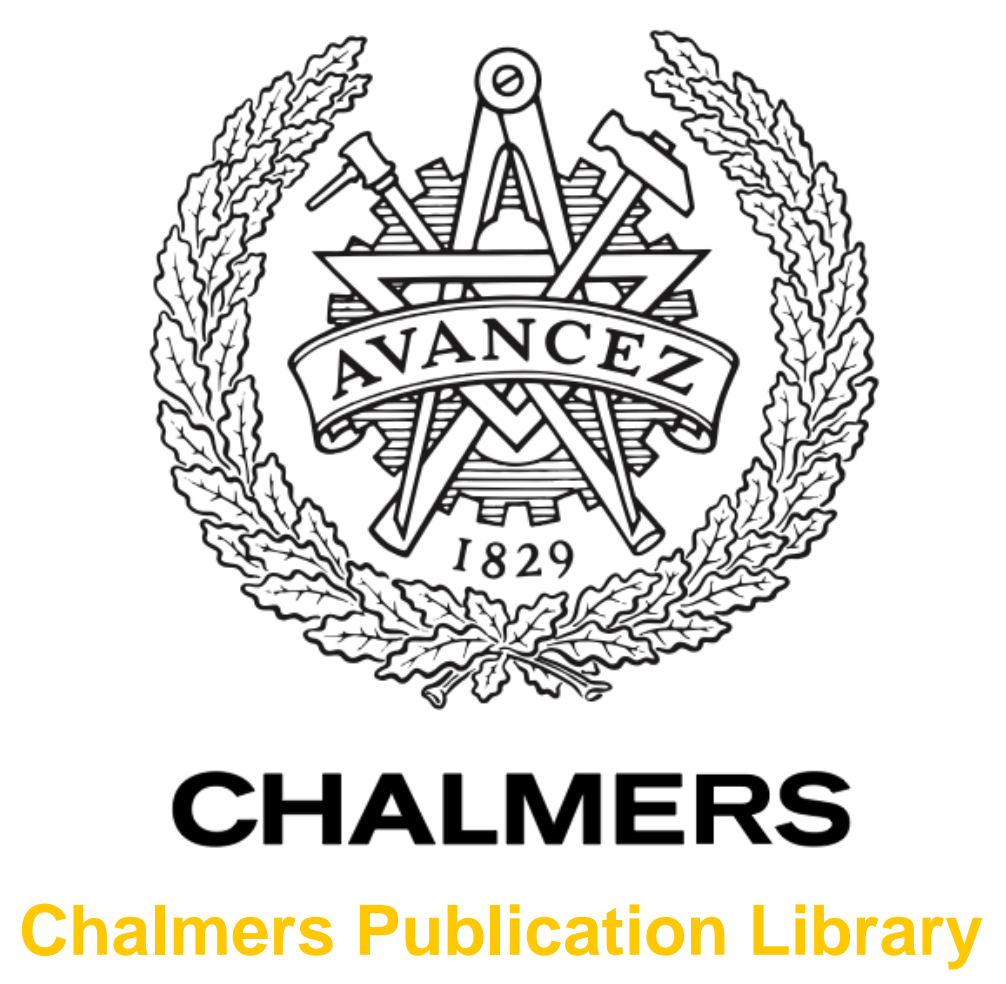

\title{
Inducement and Blocking Mechanisms in the Development of a New Industry: The Case of Renewable Energy Technology in Sweden
}

This document has been downloaded from Chalmers Publication Library (CPL). It is the author's version of a work that was accepted for publication in:

Coombs, R., Green, K., Walsh, V. \& Richards, A. (Eds): Technology and the Market: Demand, Users and Innovation. Edward Elgar. Cheltenham and Northhampton

Citation for the published paper:

Johnson, A. ; Jacobsson, S. (2001) "Inducement and Blocking Mechanisms in the Development of a New Industry: The Case of Renewable Energy Technology in Sweden". Coombs, R., Green, K., Walsh, V. \& Richards, A. (Eds): Technology and the Market: Demand, Users and Innovation. Edward Elgar. Cheltenham and Northhampton

Downloaded from: http://publications.lib.chalmers.se/publication/245980

Notice: Changes introduced as a result of publishing processes such as copy-editing and formatting may not be reflected in this document. For a definitive version of this work, please refer to the published source. Please note that access to the published version might require a subscription. 


\title{
INDUCEMENT AND BLOCKING MECHANIS MS IN THE DEVELOPMENT OF A NeW INDUSTRY: THE CASE OF RENEWABLE ENERGY TECHNOLOGY IN SWEDEN
}

\author{
A nna J ohnson and Staffan J acobsson \\ D epartment of Industrial Dynamics \\ Chalmers $U$ niversity of T echnology \\ 41296 G othenburg \\ Sweden
}

Telephone: 4631 7721213,1222

E -mail: stja@mot.chalmers.se

anjo@mot.chalmers.se

\section{INTRODUCTION}

In the past twenty-five years, a number of renewable energy technologies (RETs), for example wind turbines, have emerged in response to both oil crises and to growing environmental problems. Some of these technologies are now diffusing rapidly in the global market, and a new growth industry is emerging. ${ }^{1} \mathrm{~A}$ s is commonly the case, this growth industry is unevenly distributed across nations.

A s many authors emphasise, the study of the development of a new industry requires the use of an analytical framework which includes factors that go beyond the individual firm. These are found within the particular 'innovation system' which the firm is a part of and include institutions and networks in addition to markets. The purpose of this paper is to analyse how the Swedish innovation system has shaped the formation of a local industry that supplies RET. ${ }^{2}$

\footnotetext{
${ }^{1}$ In reality, this industry consists of several sub-industries with widely differing characteristics, but for reasons of simplicity we will treat them as one from here onwards.

${ }^{2}$ Whereas this study is limited to the case of Sweden, we will compare with other countries later on in our work.
} 
The paper is structured as follows. First, an analytical framework is developed. Second, we describe the empirical field and make a preliminary assessment of the performance of Swedish industry within RET. Third, this performance is explained empirically in terms of mechanisms inducing and blocking the industry's development. Finally, we discuss some implications for policy.

\section{ANALYTical framework}

The process by which new technology emerges and is diffused in society, thereby generating new growth industries, can be studied from a number of perspectives. The neo-classical economic perspective focuses on the influence of changes in relative prices. In contrast, seen from the perspective of the entrepreneur, the entrepreneurial act in the individual firm is the central feature. These perspectives are not irrelevant, but we will develop one which also emphasises that:

- the innovation and diffusion process is both an individual and a collective act; and that

- the determinants of firm growth are not only to be found within individual firms, but also reside in an 'innovation system' that both aids and constrains the individual firms within it.

It is the character of this innovation system, which we need to comprehend if we are to understand how new growth industries emerge.

Since 1987, when Christopher F reeman published his book on the 'J apanese Innovation System', several system approaches have been developed. Some take the country as the unit of analysis and imply that differences in their institutional set-up and structure of production (their 'national innovation systems') influence the behaviour of individual firms (L undvall, 1992; N elson, 1992; Porter, 1990). Others focus on regional innovation systems and elaborate more on cultural variables (M askell, 1997; Saxenian, 1994). Y et others have for some time studied industrial networks where firms are tied together in long lasting relationships ( $H$ åkansson, 1987). Finally, some authors focus on 'technological systems': systems built around specific technologies or products (Carlsson, 1995 and 1997; H ughes, 1983; L undgren, 1991).

A s our objective is to analyse the evolution of a new industry, it is necessary for us to employ an analytical framework, which takes into 
account factors specific to the industry supplying a particular technology or product. A technology/product-specific framework is particularly useful when competition between various technologies to perform a certain function, in this case the supply of energy, is in focus. In such cases, the competing technological systems not only generate diversity but also constitute the selection environment. ${ }^{3}$ We have therefore opted for the technological system approach as our analytical starting point.

A technological system can be formally defined as '...network(s) of agents interacting in a specific technology area under a particular institutional infrastructure to generate, diffuse, and utilize technology. Technological systems are defined in terms of knowledge or competence flows rather than flows of ordinary goods and services. They consist of dynamic knowledge and competence networks' (Carlsson and Stankiewicz 1991, p. 111).

$B$ ased on this definition, we see that technological systems are made up of a number of elements:

A ctors and their competence, technical as well as others. A particularly important set of actors are 'prime movers' or system builders (H ughes, 1983). These are firms, or other actors, which are technically, financially and/or politically so powerful that they can initiate or strongly contribute to the development and diffusion of a new technology. 0 ther key actors are those performing a 'bridging function', that is connecting actors, for example industry associations or technology transfer units at universities.

N etworks, which constitute important routes for the transfer of tacit (M etcalfe, 1992) and explicit knowledge. ${ }^{4}$ In particular, we note networks that are conducive to the identification of new problems and the development of new technical solutions (often user-supplier networks), and more general information diffusion networks. B eing strongly integrated in a network increases the resource base of the individual firm (information, knowledge and so on.) and, therefore, its degrees of freedom. The network also influences the perception of what is possible and desirable, that is images of the future, which guides

\footnotetext{
${ }^{3}$ Some technological systems can be complementary. For instance wind and hydropower are complementary in that the latter is highly flexible whereas the former is erratic in the supply of electricity.

${ }^{4}$ This and the following paragraph is based on Carlsson and Jacobsson (1997b).
} 
specific investment decisions. A t the same time, the network constrains the individual firm and limits its technology choice and growth (L undgren and N ordenlöw, 1995).

Institutions, both 'hard' ones, such as legislation or the educational system, and softer ones, such as culture. The roles of the different institutions vary; some promote a high connectivity in the system, whereas others influence the incentive structure. A s is emphasised in institutional economics (for example E dquist and J ohnson (1997)) and in the literature on innovation systems (for example Carlsson and Stankiewicz (1991) and Porter (1998)), institutions are important not only for the specific path a technology takes but also for the growth of firms.

There are many technological systems in a country or region (for example one for genetic engineering and one for wind turbines). $E$ ach of the technological systems has unique features in terms of the constellation of actors and their competence, the character of the networks and the nature of the institutions. A s a consequence, they vary in their ability to foster growth industries.

H owever, industrial growth is not only influenced by factors specific to a technological system, but also by those that a range of technological systems has in common. For instance, legislation that for many years obstructed the development of a venture capital market in Sweden influenced the access to capital for a broad range of new technology based firms (O hlsson, 1991; K aramömerlioglu and J acobsson, 2000). Thus, our analytical framework cannot be limited to the technological system approach; we also need to consider elements drawn from other system approaches, in particular those which are of more general relevance within a country (for example national innovation system).

This implies two potential problems of a methodological nature. First, how can we integrate different analytical approaches, where concepts and terms differ? Second, how do we define the borders of the system as we enlarge it with non-technology specific elements?

Integrating different system approaches is possible since a scrutiny of the literature ${ }^{5}$ reveals that the system approaches have a shared

\footnotetext{
${ }^{5}$ The following sections are based largely on Johnson (1998). The literature used covers work of the following authors: Bijker, Carlsson and Eliasson, Carlsson and Jacobsson, Carlsson and Stankiewicz, Dahmén, Dosi et. al., Edquist and Johnson, Eliasson, Galli and
} 
understanding of a set of basic functions ${ }^{6}$ that are served in an innovation system. E ach of these basic functions needs to be served if a new industry is to develop but, of course, they may be served in a variety of ways. For instance, capital can be supplied by specialised venture capital firms, customers, banks, suppliers or even firms acquiring another company. In the next paragraphs, we will elaborate on these functions. ${ }^{7}$

The first, and maybe most obvious, function is to create 'new' knowledge. ${ }^{8}$ B earing the definition of a technological system in mind, this function may also be viewed as an overall system goal.

A second function is to guide the direction of the search process among suppliers of technology and customers, that is influence the direction in which actors deploy their resources. This function includes providing recognition of a growth potential (for example in terms of identifying technological opportunities and commercial viability), which is closely connected to the legitimacy that a new technology has in the eyes of various actors. It also includes guidance with respect to the choice of specific design configurations, for example through the identification of problems of a technical nature, changing factor prices, relationships to competent customers or various policy interventions.

A third function is to supply resources, that is capital, competence, and other resources. Capital is needed to distribute risks and may come with competence, for instance in the form of venture capital. Competence refers to a whole range of competencies, including technological. $Y$ et another type of resource may be those which are complementary to the new product.

A fourth function is to facilitate the creation of positive external economies through the exchange of information, knowledge and visions. This function is a central part of the systemic approach to innovation and involves the formation of networks and meeting places and, perhaps, a change in culture.

Teubal, Hughes, Håkansson, Lundgren, Lundvall, Nelson, Porter, Saxenian. For detailed references, see Johnson and Jacobsson (1999).

${ }^{6}$ That is the contribution of a single component, a set of components or the entire system to the system's (inexplicit) 'goal'.

${ }^{7}$ In addition to the functions, there are a set of general incentives to innovation and firm growth, which are recognised in many approaches. For examples, see Johnson and Jacobsson (1999).

${ }^{8}$ For example through R\&D, learning by everyday activities or imitation. 
A fifth function is to facilitate the formation of markets. M arkets are not always created in a spontaneous fashion but sometimes need to be stimulated, or even created. Some important aspects of facilitating the formation of markets may be to clear legislative or political obstacles and stimulate social acceptance by legitimising the new technology.

The shared view among the system approaches of these fundamental functions permits us to integrate elements from different approaches. The functions also provide us with a tool for an empirical delineation of the system. In the context of an emerging technological system, we can define its borders by analysing what promotes or hinders the development of these functions. These factors may be fully technology specific, but may also influence several technological systems simultaneously. H ence, they can be derived from a system perspective using different units of analysis: technology, industry and nation.

A s mentioned above, all of these functions need to be served for a new industry to evolve and perform well, but there is a number of potential obstacles. Conventionally, these obstacles would be referred to as 'market failures'. We refrain from using that terminology, as it is not meaningful to refer to deviations from a (neo-classical) 'optimum' in an uncertain, dynamic and complex world. Instead, our objective is only to find obstacles to the development of these functions in an emerging technological system, that is factors that tilt the selection environment in favour of incumbent technologies. These factors are found in the nature of actors and markets as well as in networks and institutions (Carlsson and J acobsson, 1997a). A non-exhaustive list of obstacles and corresponding functions is found in table 2.1 and discussed below.

TA BLE 2.1: Examples of O bstacles to the Formation of P owerful Functions ${ }^{1}$

\begin{tabular}{|c|c|}
\hline OBSTACLES & FUNCTIONS \\
\hline \multicolumn{2}{|l|}{ A ctors and $\mathrm{M}$ arkets } \\
\hline $\begin{array}{l}\text { Poorly articulated demand } \\
\text { 'L ocal' search processes }\end{array}$ & $\begin{array}{l}\text { Create knowledge, guide search, facilitate market form. } \\
\text { G uide search }\end{array}$ \\
\hline $\begin{array}{l}\text { E stablished technology } \\
\text { characterised by increasing returns }\end{array}$ & G uide search, facilitate market form. \\
\hline$M$ arket control by incumbents & G uide search, facilitate market form. \\
\hline \multicolumn{2}{|l|}{ Networks } \\
\hline $\begin{array}{l}\text { Poor connectivity } \\
\text { W rong guidance with respect to } \\
\text { future markets }\end{array}$ & $\begin{array}{l}\text { Create external economies, facilitate market form. } \\
\text { G uide search, facilitate market form. }\end{array}$ \\
\hline \multicolumn{2}{|l|}{ Institutions } \\
\hline $\begin{array}{l}\text { L egislative obstacles } \\
\text { Failures in the educational system }\end{array}$ & $\begin{array}{l}\text { G uide search, facilitate market form. } \\
\text { Supply resources }\end{array}$ \\
\hline
\end{tabular}


Skewed capital market

U nderdeveloped organisational

and political power of new entrants

0 bstacles related to actors and markets may be prominent features of the selection environment and can shape the functions in several ways, thereby influencing the process of formation of a new technological system. Some examples are given below.

In the early phase of the diffusion of a new technology, potential customers may not be able to articulate their demand (in terms of price/performance) and meet the supplier in the market place. In the absence of articulated customers, suppliers may neither receive the proper guidance for their search process nor be able to create new knowledge. A part of the formation of markets may therefore be the formulation and articulation of the demand from a set of fragmented, potential customers.

'L ocal' search processes imply that the search space for new opportunities (D osi, 1988) and problem solutions (B ijker, 1995; Fransman, 1990; H ughes, 1983) may be constrained; actors may build upon their existing knowledge base when they search for new opportunities (D osi, 1988). This tends to restrict their technology choice to closely related areas in terms of both technologies and markets (D osi et. al., 1990). H ence, history will guide the direction of the search process of the firms by influencing their ability to recognise new opportunities for growth.

$M$ any new technologies suffer from facing incumbent substitutes which have undergone a process of 'increasing returns' (A rthur, 1988). Thus, new products tend to have a high relative price (lack of scale and experience economies) and/or relatively low utility (poor performance, lack of network externalities and/or complementary products), which hinders the formation of markets and may guide the search process to other fields.

$M$ arket control by dominant incumbents means that the selection process may not involve a 'free' choice by customers. M arkets may therefore not be formed which may guide the search process of firms to other fields.

The selection environment is also made up of networks and institutions. Like markets, networks do not necessarily grow spontaneously. A s Saxenian (1994) argues, there may be institutional and organisational obstacles to the growth of a collective identity. If so, a 'weak' network failure would arise in the sense that actors are not 
well connected to other actors. The system may then fail in the creation of positive externalities, and be unable to reduce social uncertainty about the new technology.

A different form of network failure - a 'strong' failure - could occur if individual firms are guided by others (that is by the network) in the 'wrong' direction and/or fail to supply one another with the required knowledge. The source of a strong network failure lies in differing assumptions concerning future (missing) markets within various networks. Thus, the minus side of tight networks is that these contain considerable inertia. Competence will then be 'locked-in' and social acceptance (legitimacy) of the new technology will be delayed.

Institutions may fail to shape a propitious context for the formation of a new technological system. For example, current legislation may guide the search process towards the 'incumbent' technology by influencing relative prices of different alternatives. The educational system may fail to react quickly enough to the emergence of new technologies and therefore negatively influence the supply of competence and, as a consequence, the ability to identify and exploit new opportunities. The capital market may not respond 'spontaneously' to the need of a new technological system (Carlsson and J acobsson, 1997b), which would influence the supply of both capital and competence. This would, in turn, influence the legitimacy of the new product and, therefore, guide firms in their search process. Finally, a new technology may suffer from weakly organised actors. For example, industrial associations may be weak, which may lead to a poor ability to articulate the need for legislative change and influence the supply of competence. Lack of organisational power may also influence social acceptance of the new technology and the formation of meeting places for the exchange of information and knowledge.

Clearly, there is a range of obstacles to the formation of powerful functions needed for the evolution of new industries, which may act independently but are likely to reinforce one another. For instance, a strong network failure would reinforce local search processes or lead to an absence of pressure for legislative change in favour of the new technology. Indeed, the existence of these potential obstacles would lead us to expect that the formation of a new industry is a process that is long and hard to predict.

In the empirical analysis in section four, we will trace how the nature of actors, markets, networks and institutions shaped the formation of 
the Swedish industry supplying renewable energy technology. N ext we will introduce the reader to the technologies studied and provide a preliminary assessment of the performance of Swedish industry in this field.

\section{THE TECHNOLOGIES AND AN ASSESSMENT OF SWEDISH PERFORMANCE}

O ur enquiry is focused on wind turbines, solar collectors and equipment for biomass combustion and gasification. Wind turbines produce power, solar collectors produce heat and biomass is primarily used in heat production, but can also be used as a fuel in a power plant. In the biomass field, we focus on biomass gasification for combined heat and power ( $\mathrm{CHP}$ ) production and on conventional combustion technology for heat production in different applications.

\subsection{W IND TURBINES}

Wind turbines of modern design and application date back to the end of the 1970s, but the accumulated capacity in the world did not exceed $2 \mathrm{GW}$ until 1991. The rate of diffusion has been quite high since then; the annual average cumulative growth rate between 1990 and 1998 was nearly 25 per cent, reaching a capacity of $10 \mathrm{G} \mathrm{W}$ in 1998 (J ohnson and J acobsson, 1999; BTM , 1999). The largest markets ${ }^{9}$ in the 1990s (19921997) were G ermany, India, D enmark, Spain and the N etherlands. Sweden trailed behind and ranks as number six in terms of stock per capita (J ohnson and J acobsson, 1999).

There are currently seven Swedish firms in the business of manufacturing wind turbines. Three design large or medium sized turbines ( $250 \mathrm{~kW}-3 \mathrm{M} \mathrm{W}$ ) and four very small turbines $(<100 \mathrm{~kW})$. $\mathrm{N}$ one of the firms designing large turbines have begun series production and the firms producing small turbines supply very few units. Thus, although there is a fair number of firms active in the industry, the Swedish market share is negligible.

The technological strength of Sweden is not negligible, however. In the general field of mechanical and electrical engineering Swedish industry is quite strong technically. In the specific field of wind turbines,

\footnotetext{
${ }^{9}$ The data refer to net increase in stocks.
} 
sectoral research, development and demonstration ( $R D \& D$ ) money of some magnitude has been spent within government-funded

programmes. This has resulted in competence to design very large wind turbines, the development of a unique light weight wind turbine design, competence as well as an innovation in the field of generators (directdrive generator) and advanced competence in development tools for the analysis of aerodynamic properties of wind turbines.

$\mathrm{H}$ owever, very little money from industrial sources has, so far, been spent on technological development, but this may be about to change. O ne of the Swedish firms, N ordic Windpower, recently (N ovember 1998) received funding from a number of venture capital firms and changed from being a development company to one with greater ambitions. A nother firm, $\mathrm{K}$ vaerner Turbin (with a history in the industry from 1977), which until recently had only supplied a couple of very large wind turbines to government sponsored programmes has now a growing interest in the currently expanding offshore market.A $t$ the same time, several new firms have entered the industry, supplying very small turbines.

\subsection{S O LAR COLLECTORS}

Solar collectors also date back to the end of the 1970s. The annual demand in E urope increased from a little over $200000 \mathrm{~m}^{2}$ in 1990 to $500000 \mathrm{~m}^{2}$ in 1994, which corresponds to an annual cumulative growth of about 15 percent (J ohnson and J acobsson, 1999). The total installed glazed collector area in E urope was about 4.6 million $\mathrm{m}^{2}$ in 1994, corresponding to an energy supply of roughly $2.7 \mathrm{TWh}$ /year (E SIF, 1995). The installed area in J apan and the U S was approximately 6 and 5 million $\mathrm{m}^{2}$ respectively, which suggests that the world production of energy by solar collectors was roughly $9 \mathrm{TWh}$ /year. Since 1995, the diffusion of solar collectors has increased greatly in several $\mathrm{E}$ uropean countries. In Germany, the annual market grew almost 170 percent from 1994 to 1998 (M angold, 1999), and the A ustrian market seems to have stabilised on approximately $200000 \mathrm{~m}^{2}$ per year (W eiss, 1999). ${ }^{10}$

The largest E uropean markets (excluding $\mathrm{G}$ reece) are A ustria and Germany. Sweden ranks as number 6 in terms of stock per capita, due to an early diffusion of some magnitude. However, in the 1990s the

\footnotetext{
${ }^{10}$ We have not been able to locate data for Europe as a whole.
} 
Swedish market has stagnated whereas those in other E uropean countries, in particular in D enmark, Switzerland, G ermany and A ustria, have developed very well. Thus, the Swedish market is falling even further behind those of other E uropean countries (J ohnson and J acobsson, 1999).

A s in other countries, the Swedish industry supplying solar collectors consists of small firms. The largest, T echnoterm, has a sales volume of roughly $10000 \mathrm{~m}^{2}$ and there are even a few smaller firms with an annual supply of a few hundred $\mathrm{m}^{2}$.

Swedish firms do not normally export solar collectors but Technoterm has a large share of the E uropean market for absorbers (20 percent). I mports are frequent (E SIF, 1996), which means that the market share of Swedish firms is less than the Swedish share of the annual E uropean instalments of complete solar collectors. The latter was less than three per cent in 1994 (E SIF, 1995).

A bout half of the Swedish market is a 'do it yourself'market (E SIF, 1996), aimed at a small niche of 'green' customers. This clearly shows its underdeveloped status. ${ }^{11}$ There are, though, some efforts being made to reach new market segments, such as building companies, real-estate companies and hospitals. This market diversification is stimulated both by academic initiatives and by government programmes. R ecently a more powerful actor has entered the industry from a related industry (tanks for accumulating heat), which may mean that these new segments will be approached with greater force.

In terms of technological competence, the Swedish position is somewhat better. There is substantial experience in large scale applications since Sweden was among the pioneers in building district heating systems, sponsored by government R D \& D (A ndrén, 1998; $E S I F, 1996)$. The academic competence is relatively strong and the leading energy company in Sweden (government-owned $V$ attenfall) is pursuing advanced $R \& D$ in solar collectors. Finally, as mentioned above, Technoterm has a strong E uropean position in the absorber field.

\footnotetext{
${ }^{11}$ In the larger and very rapidly growing Austrian market, this share was only 20 percent in 1996 (IEA, 1998).
} 


\subsection{BIOMASS}

In the biomass field, diffusion is very substantial in Sweden as compared to the rest of E urope. Whereas biomass contributed to about 91 TW $h$ in 1997, which amounted to 19 percent of the energy supply in Sweden (STE M , 1998), the total for the E uropean U nion was approximately 520 TW h (E uropean Commission, 1997). This figure is, however, expected to have tripled by the year 2010 (E uropean Commission, 1997), implying an expected average cumulative growth rate of almost 9 percent.

In Sweden, biomass is increasingly being used in CH P production and more advanced technical solutions based on gasification are being developed and tested for that purpose. M oreover, nursing homes, schools and hospitals are beginning to use biofuelled boilers for heating, and pellet burners are diffusing to single households. In connection to these new applications and technologies, a system of related products and services is developing (equipment and plants for fuel production, fuel distribution systems, quality approval procedures and so on.).

In many of these areas, Swedish firms are pioneers. This applies to technology to use gasified biomass, where TPS and K vaerner Chemrec are in the international forefront technically (but we have yet to see the first full-scale applications in the Swedish market). It also applies to pellet burners for single households where there are now about 20 small Swedish firms producing burners. There is a substantial production of pellets, primarily for district heating plants, and there are some strong Swedish suppliers of biofuel boilers for medium sized applications (such as schools). These Swedish firms have a good position locally, especially in the heating segment, but do not export to any great extent. Finally, the level of Swedish competence with respect to combustion of biofuels and related technologies is quite high; Sweden has a long tradition of burning such fuels, and a substantial amount of money ( 700 million SE K ) has been channelled into academia via governmental programmes for research on combustion technology in general (SOU, 1992).

The picture that emerges is one where the technical competence in Sweden is quite high in RET. H owever, the performance in terms of both the diffusion and, in particular, the development of a Swedish supplier industry, is questionable. W ith the exception of Technoterm in 
solar collectors and a few firms supplying medium sized biomass

boilers, the results are quite meagre in terms of growth of new firms.

\section{INDUCEMENT AND BLOCKING MeChANISMS ${ }^{12}$}

In this section, we will attempt to explain the pattern above in terms of the workings of a set of mechanisms that induce or block the development of powerful functions of the nature discussed in the analytical framework. In table 4.1, we specify these mechanisms and show which functions they have had affected. We will thereafter analyse each of these mechanisms.

TABLE 4.1: Inducement and blocking mechanisms

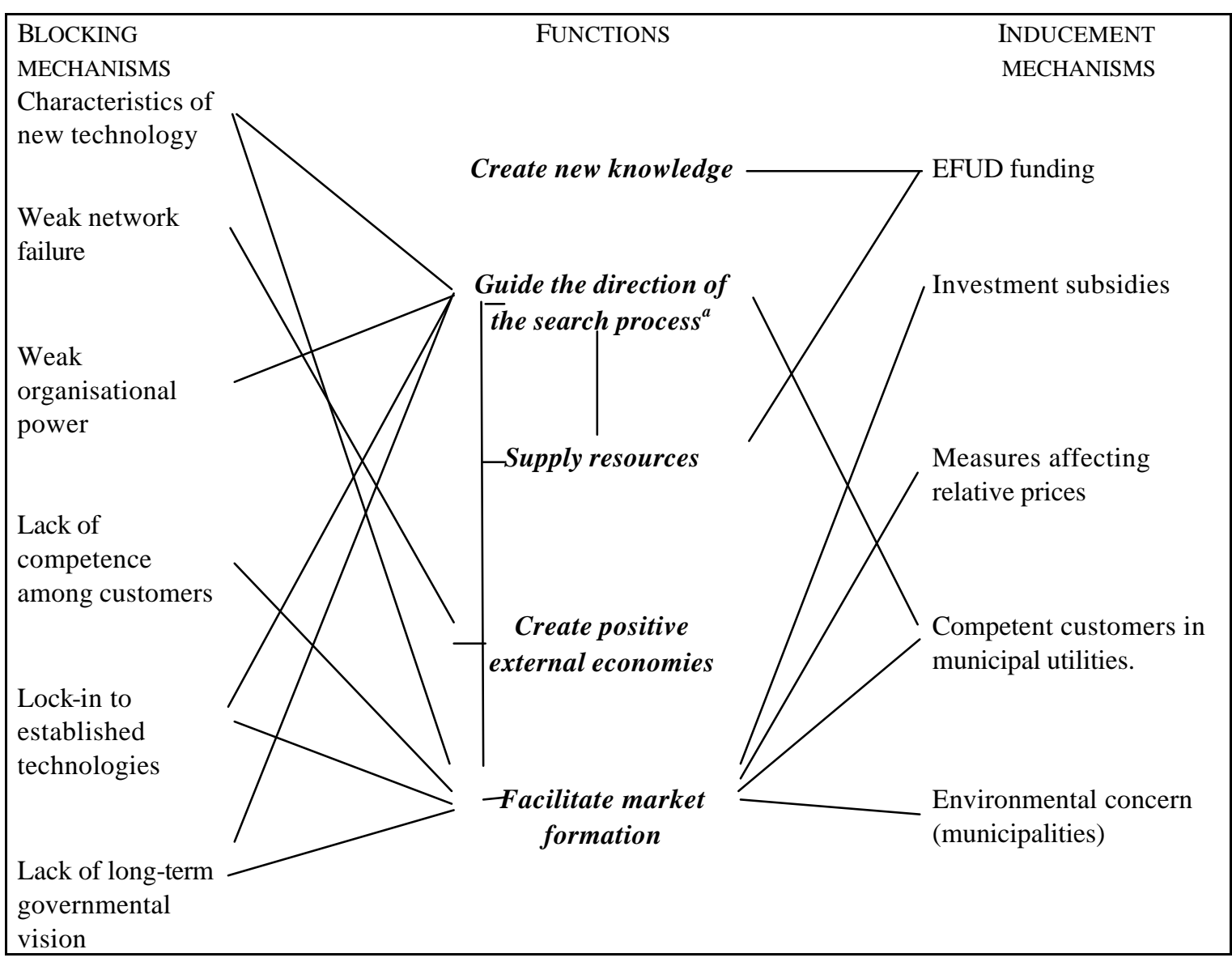

${ }^{\text {a }}$ R ecognise potential for growth, guide technology choice and legitimise.

\footnotetext{
${ }^{12}$ This section is based on interviews with a number of firms supplying renewable energy technology, industry associations, customers and so on. For more information, see Johnson and Jacobsson (1999).
} 


\subsection{INDUCEMENT MECHANISMS}

M ost of the inducement mechanisms emanate from government policy measures. The relative importance of these measures differs between technologies, although a few of them apply to the whole field.

\subsubsection{EFUD FUNDING}

In 1975, Swedish government began funding programmes for research, development and demonstration in the energy field (E FU D programmes). The late 1970s and early 1980s were characterised by an ambition to decrease the dependency on oil, which resulted in programmes oriented towards applied $R \& D$ and demonstration (IV A , 1992). These were sizeable compared to other OECD countries (J ohnson and J acobsson, 1999).

In the mid-1980s, the programme was redirected towards long-term and basic research and the EFUD activities moved from industry to academia (IV A , 1992). M oreover, the size of the programmes was substantially reduced, which particularly affected the development, demonstration and commercialisation part of the programme (E nergiforskningsgruppen, 1992).

In total, approximately 4.5 billion SE K of E FU D funding have been channelled into the field of renewable energy sources. Of this funding, bioenergy, wind power and solar energy have received approximately 50, 20 and 30 percent respectively (J ohnson and J acobsson 1999). So far, the results have primarily been increased knowledge and competence in the field of RET, especially within academia, and the creation of new networks between actors with related activities.

\subsubsection{INVESTMENT SUBSIDIES}

In the 1990s, the redirection of E FU D towards basic research was partly compensated by investment subsidies aiming at promoting market formation. The support for bioenergy has again dominated; out of a total funding of approximately 2.6 billion SE K, almost 80 percent has been directed towards bioenergy, especially CH P plants. Thus, the relationship between support for technological development and support for market formation is almost one to one in this field. In contrast, the focus on RD\&D is apparent in the fields of wind power and solar energy, where market support has only amounted to 30 and 25 percent of the E FU D funding. 


\subsubsection{MeASURES AFFECTING RELATIVE PRICES}

Government has also implemented measures to stimulate market formation by changing relative prices. The energy and carbon dioxide taxes on fossil fuels are higher than on RE Ts. Small-scale (1,5 M W) producers of electricity are guaranteed a minimum price (currently a good $0.03 \cup \mathrm{SD} / \mathrm{kWh}$ ), which provides them with a market for their surplus electricity. In the wind power field, producers receive an environmental bonus of approximately $0.01 \mathrm{U} S \mathrm{SD} / \mathrm{kW} \mathrm{h}$. H owever, in spite of these measures, the relative prices are unfavourable except for biofuel-based heat production.

\subsubsection{COMPETENT CUSTOMERS AND ENVIRONMENTAL CONCERN}

In addition to government policy, there are two other main inducement mechanisms. First, municipal energy companies are very competent customers. They can articulate a demand, which not only helps in the process of market formation and guides the direction of search for suppliers but also creates legitimacy for the RETs, in particular for biofuelled boilers. Second, the general concern for environmental issues stimulates market formation. A gain, this is especially apparent for municipal energy companies, which often choose environmentalfriendly technologies, but there is also a growing demand from industry for 'green electricity', for instance from the Swedish R ail company.

\subsection{BLOCKING MECHANISMS}

\subsubsection{CHARACTERISTICS OF NEW TECHNOLOGIES}

Some blocking mechanisms are inherent in situations where new firms are trying to enter an established market with new and unknown technologies and are, thus, present in all technological areas (including RET) and innovation systems. The incumbent technologies are well known and legitimate and have a better price/performance ratio, partly due to processes of increasing returns to adoption. In addition, customer uncertainty with respect to the technological performance and the economic benefits of the new substitute is often large. Some functions, for example stimulation of market formation and direction of the search process, may therefore not be adequately served.

H owever, the impact of blocking mechanisms due to technology characteristics may vary between innovation systems, since innovation systems have different abilities to counteract them. Thus, the important 
thing to notice in the Swedish RET case is not the mere presence of such blocking mechanisms, but rather the failure of the Swedish innovation system to balance their negative impact by ensuring that neglected functions were served in other ways.

\subsubsection{WEAK NETW ORK FAILURE}

The relationships between $\mathrm{RET}$ firms are generally very weak. For the larger firms, this lack of co-operation may be due to a lack of potential partners; for example, there are only two or three producers of largescale biofuel boilers in Sweden. For small firms, the poor connectivity of the system may partly be due to lack of information about other actors. M any small RET firms also are fairly individualistic, which makes them unwilling to co-operate and share their knowledge with other firms. In addition, some of the RET firms which have been in business for some time are somewhat antagonistic to new entrants. This antagonism is especially apparent within the fields of solar collectors and small and medium-scale biofuel combustion technology; in fact, a quality certification procedure for solar collectors was developed partly as a means to eliminate small, 'unprofessional' producers from the market. ${ }^{13}$

There are weak relationships between RET firms and firms providing related products and services, such as installation firms, suppliers of fuel and so on. Poor connectivity between RET firms and the users is also common in all three fields. There are a couple of exceptions, though. Some bioenergy firms have continuous relationships with their customers and use them for technological development, and $V$ attenfall has been strongly connected to several of the Swedish wind turbine manufacturers.

Connectivity between RET firms and academia is of varying quality; whereas the firms with large-scale or advanced technology have welldeveloped relationships with different universities or technical institutes, ${ }^{14}$ most firms with small-scale or simpler technology have had little or no such contacts. The lack of connectivity is not only due to lack of information about academic research and personnel but also to a large cultural distance between the two groups.

\footnotetext{
${ }^{13}$ It costs too much for many small firms, even though their products may very well be good enough to pass the tests.

${ }^{14}$ In fact, several of these firms are spin-offs from universities or technological institutes.
} 
H ence, although there are some exceptions, the connectivity between actors can be considered to be poor in the whole system. This means that positive external economies will not be properly generated, which has a set of implications.

First, there is an absence of the learning element in strong usersupplier relationships where the user provides an input to the innovation process, both by articulating its demand and providing feedback of technical nature. $O$ ne result of this absence is a focus on performance rather than on price/performance ratio in the fields of solar collectors.

Second, problems are poorly, and wrongly, specified and the responsibility to solve problems falls between stools. This effect is especially apparent for solar collector and pellet burners. For example, customers have experienced a problem with their pellet burners, which is a consequence of burners and fuel not being adapted to each other. Pellet manufacturers claim that it is due to the burner, whereas pellet burner manufacturers blame it on irregular fuel quality. Collaboration between these firms, which have a common interest in the expansion of the market for pellet burners, would probably have led to a clearer articulation of the problem. A s Chalmers $U$ niversity of Technology does research on related issues and already knows the cause of the problem, a solution would have been found through a close relationship with these researchers.

Third, weak links between RET firms and users make it difficult to exchange information, for example about existing technical options and their relative performances, which creates customer uncertainty and, thus, blocks market formation. $M$ arket formation is also blocked by a poor connectivity between RET firms and firms supplying complementary products, which causes customers to experience problems with co-ordination and uncertainty about the overall responsibility for the project.

\subsubsection{WEAK ORGANISATIONAL POWER}

There are basically three industry associations for renewable energy in Sweden, one for each renewable energy source: SV E BIO (the Swedish B ioenergy A ssociation), SE A S (Solar E nergy A ssociation of Sweden), and SVIF (Swedish W ind Power A ssociation). In addition, SE RO (The $N$ ational O rganisation of Swedish E nergy A ssociations) works within all three fields (and some others) to promote domestic energy sources. 
H owever, with the exception of SVE BIO, these associations are relatively weak and lack resources. They have problems influencing policy and creating legitimacy for the new technologies, which blocks the recognition of the field as a potential growth area. M oreover, weak associations cannot function as bridging institutions and convey industry problems to, for example, academia.

\subsubsection{LACK OF COMPETENCE AMONG POTENTIAL CUSTOMERS}

$M$ any of the RETs open up new market segments. Small-scale products (for example pellet burners, solar collectors and small wind turbines) are suitable for single households; medium-scale products (for example some biofuel boilers) are used by industrial firms or by municipalities and county councils (in schools, nursing homes, hospitals and so on.); some large-scale products (for example black liquor gasification plants, large biofuel boilers and so on.) are aimed at industrial firms. This market diversification for energy technology is plagued with several problems which hinder market formation.

$W$ ith the exception of industrial firms, these new segments are not used to making this type of investment decisions. For example, county council purchasers who usually buy standard products (for example paper plates) in large quantities for hospitals and nursing homes do not necessarily have the competence needed to make investment decisions about energy production equipment. Single-house owners make this type of investment decision maybe once every thirty years when their boilers are to be replaced. Thus, in many cases, new customers lack the competence needed not only to invest in RET but also to articulate their demand.

Whereas acquiring this competence is a learning process for some, say municipal authorities and owners of apartment houses, many of these segments can neither be expected to gain the necessary competence to invest in renewable energy technology in a reasonably cost-efficient way, nor to be able to articulate their demand. Intermediaries therefore need to come forth. However, with the exception of the wind power field there is a lack of such intermediaries. Hence, slow market formation is not only the result of incompetent customers but also of a lack of 'bridging institutions'. 


\subsubsection{LOCK-IN TO ESTABLISHED TECHNOLOGIES}

The ambiguous acting of some of the established customers (especially the large power companies) blocks market formation. For example, although $V$ attenfall has made investment in $R D \& D$ and states its commitment to renewable energy sources, it had only bought 4 commercial wind turbines by 1990 and 38 by 1998 (A verstad, 1998). This type of ambiguous behaviour adds to the uncertainty perceived by other customers, firms and investors. Thus, the power companies influence the demand not only directly (by not buying the equipment), but also indirectly (by blocking the creation of legitimacy and the recognition of potential for growth).

This ambiguity presumably reflects a lock-in phenomenon due to 'local search' among the big power companies who favour large-scale technologies. ${ }^{15}$ The interest in large-scale technologies clearly follows the pattern at $V$ attenfall, which is dominated by hydro and nuclear power. These technologies have been the measures by which all new technologies have been assessed. Since only such large-scale technologies can have a significant influence on the power balance in the short and medium run, other technologies have been deemed to be of little interest.

The inclination towards large-scale technologies became even more evident as $V$ attenfall had to follow government instructions to prepare for the phasing-out of nuclear power. The strengthened inclination had implications not only for the continued choice of wind turbines in $\mathrm{M} \mathrm{W}$ size (which induced $K$ vaerner to continue to develop these (a strong network failure)), but also for the rejection of a new biomass gasification process, which was not as large-scale as the one $V$ attenfall favoured in the early 1990s.

The lock-in of these actors is but a part of a larger phenomenon related to norms and values in the society at large regarding energy technologies. Sweden as a whole seems to be caught in a 'nuclear power trauma', which reduces all energy issues to one: the phasing-out of nuclear power. R enewable energy is seen, by politicians and others, only as a means to replace nuclear power and all programmes to induce further diffusion of RETs are justified in that context.

\footnotetext{
${ }^{15}$ This is not a uniquely Swedish problem, see European Commission (1999).
} 
This trauma has two consequences for RET. First, in general (and not only for $V$ attenfall) the value of each $R E T$ is judged in relation to how many nuclear power reactors it can replace. For small scale technologies, it is but a fraction, at least in the short and medium term, which further weakens the legitimacy of RET and contributes to an inability to recognise the growth potential of $R E T .{ }^{16}$

Second, RET is perceived by many as a threat to the continued availability of cheap nuclear power and, therefore, as a threat to Swedish industry and welfare. The consequent lack of legitimacy of RET in the eyes of industry and large parts of the media has influenced, in a strongly negative fashion, all the basic functions that need to be fulfilled if a new industry is to be formed. In particular, the search process has been directed away from renewable energy technologies, which has constrained the supply of resources flowing into the field and obstructed the process of market formation. It is notable in this context that none of the large Swedish firms have entered the industry even though it clearly needs a 'prime mover'.

\subsubsection{LACK OF LONG-TERM GOVERNMENTAL VISION}

A lack of a long-term governmental vision of the role of RETs in the Swedish energy system has blocked the functions in several ways. First, as long as the government's expectations of the future of RETs in Sweden are unclear, the technologies will continue to lack legitimacy and their growth potential in the global market will not be recognised. Second, the lack of a governmental vision results in inconsistent policy measures, which have led to an erratic demand, biases in the technology choice away from new technology and undue uncertainties.

G overnment attempts to stimulate the market for RET directly through subsidies have resulted in large fluctuations in the market. For example, when government announced its intentions to investigate whether or not to subsidise pellet burners, the market ceased to exist until the decision was made and the subsidies implemented. L ater, when the funds for a particular year were finished, government

\footnotetext{
${ }^{16}$ There are even some indications that incumbent actors are afraid to promote the development of RET since they believe that, by doing so, they will provide the government with an excuse to shut down all nuclear power plants.
} 
announced the possibility of new subsidies the following year, which destroyed the market once more.

A $n$ equally serious effect of time-limited investment subsidies is that they may lock-in the market to old technology unless technological newness is a prerequisite for receiving support. For example, the CH P support (1991-1996) attracted customers who would have been interested in investing in new gasification technology. This occurred even though there were also polices promoting the development of that technology; the support was not high enough to compensate for the higher technological risk. Now, these customers have all invested in conventional CH P technology, which makes Sweden a 'dead' market for the new gasification technology.

There are further inconsistencies magnifying uncertainties for prospective investors. O ne source is related to parts of the legislation and regulations, which counteract the effect of market stimulating measures. In particular, due to unclear rules for granting building permits for wind turbines, customers hesitate to make the investment.

There is also an uncertainty about the future levels of taxes on alternative fuels, which increases the (inherent - see above) difficulties for customers to estimate the economic benefits of the RET. The taxation rules have been altered a number of times, which has led to substantial changes in RET competitiveness. For example, in the tax reform of 1993, industry was relieved of the energy tax and received large reductions in the $\mathrm{CO}_{2}$ tax, which deprived biofuels of their earlier advantage.

\section{IMPLICATIONS FOR POLICY}

In order to develop an industry supplying RET, as well as speed up the local diffusion of RET, there is a need for policies to address all the blocking mechanisms discussed above. First and foremost, policy must unlock the 'nuclear trauma', nurtured over a period of two decades. ' $U$ nlocking' requires the separation of the nuclear issue from the renewable one.

This should not be difficult, in principle, because the electricity market is no longer national - it is $\mathrm{N}$ ordic and is beginning to be a E uropean market. Hence, due to deregulation and internationalisation, the energy market is no longer a closed market where the diffusion of one technology (for example wind power) entails the replacement of 
another (for example nuclear power). This opens up for any country to become a large net exporter of electricity. The potential to develop a large net export of 'clean' electricity is particularly significant in the era of 'global warming.' Policy makers must therefore stop motivating investments in RET with a need for replacing nuclear power. They should instead work towards the fulfilment of a E uropean electricity market where power can be exported in larger quantities from Sweden and, induced by appropriate legislation, replace electricity generated by fossil fuels on the continent. O nly then can we bypass the trauma and open up for a larger interest in RET by the business sector, financial institutions and potential customers.

Second, policy makers need to develop a vision of a future energy system with a substantially larger RE T component. Such a vision is necessary in order for uncertainty to be reduced, for legislative changes to take place and for existing legislation to be an interpreted in a manner which speeds up the diffusion process, for instance by government bodies dealing with building permits for wind turbines. A vision is also required for various types of intermediaries, both firms and municipal authorities, to be formed in greater numbers and aid in the process of forming new markets.

W ith an explicit vision it will be easier to develop consistent policies promoting $\mathrm{RET}$. which is of central importance to reduce the uncertainty inherent in new substitutes. H owever, not only consistency but also timing of market stimulation measures is important to the local supplier industry. In the wind turbine field, Swedish market stimulation programmes began in 1991, several years after D enmark, G ermany and H olland (Carlman, 1990). N ot surprisingly, these countries were able to develop a supplier industry based on the local market. In the solar collector field, an early Swedish market stimulated the emergence of a local supplier industry. A s market stimulation policies ended in Sweden while they greatly expanded abroad in the 1990s, the Swedish suppliers are now disadvantaged compared to their competitors in G ermany, D enmark and A ustria. In biomass, Swedish suppliers are presently in an advantageous position as the local market is relatively large, but we have yet to see a first large-scale investment in gasified biomass and the suppliers of pellet and biofuel burners have yet to become strong internationally. $\mathrm{H}$ ence, a patient policy stimulating the market is also required. 
The specific policy measures may be of various sorts but must be based on an understanding of the precise nature of the blocking mechanisms. In acquiring that understanding, two features of the evolution of a new industry need to be borne in mind:

First, in the diffusion of a new technology, we may distinguish between the first niche markets that consists of early adopters; bridging markets that allow for larger volumes of production and mass markets, that will make the product a commodity. The technological system needs to fill the various functions throughout the life of the industry, that is not only in the initial creation of niche markets, but also in the transition to bridging and mass markets. For instance, in the case of solar collectors, we are presently in the transition phase from the first niche markets of 'green' single house owners to bridging markets of, for example, real estate companies. For a transition to take place, these new segments must find solar collectors a legitimate technology and the producers of solar collectors need to be guided in their search processes to the specific needs of these new segments. In addition, a successful transition involves developing new user-supplier relations (create new networks) as well as acquiring new resources (supply of capital and complementary resources). Policies must, therefore, be designed to strengthen the functions that are weak in this particular transition period.

Second, there must be an awareness that there are various feedback loops in the innovation and diffusion process ( $\mathrm{K}$ line and $\mathrm{R}$ osenberg, 1986) and in the evolution of a new cluster (Porter, 1998). This means that policies may have a greater effect than what is initially anticipated. A gain, in the case of solar collectors, a procurement policy which identifies, educates and organises potential customers would presumably strengthen not only the formation of new markets but also foster new networks between customers and suppliers (facilitating the creation of external economies) and improve the legitimacy of solar collectors.

B earing these features in mind, the policy objectives may include an improvement in the price/performance of RET. The precise policy measures can be wider than investment subsidies; policies making sure that the RETs' distinct environmental advantage is reflected in the relative price of energy are just as important. M oreover, given the inherent uncertainties involved in investing in new technology, policy 
should favour instruments that give a high degree of predictability to the outcome of an investment.

Policy may also be aimed directly at the supplier industry. Lack of organisational strength of the new industry has contributed to the poor legitimacy of renewables, with all its implications. The firms simply need industry associations that can participate in the political process. There is, therefore, a need for policies that improve the organisational strength of the new industries.

W ith some exceptions, there are weaknesses in the networks; in the relations between the firms, their customers and academia. A s networks are conducive to the diffusion of resources, guide the search process of firms, influence what is recognised as a potential for growth as well as the formation of markets, the underdevelopment of the networks have led to problems with all the functions necessary for the formation of the new industry. Policies are therefore required to induce more dense networks and create bridging institutions.

Procurement policies have a potential to influence several of the functions. $N$ ot only do they influence market formation in a very direct way but they may also guide the search of supplying firms and by building new networks, facilitate the creation of external economies. Procurement can be implemented within the framework of specific programmes but large power companies, such as $V$ attenfall, which, by the very nature of its dominant position, should not be allowed to continue to act like any other customer, can also undertake it.

\section{REFERENCES}

A ndrén, L. (1998), Interview with Lars A ndrén, SE A S. A pril $17^{\text {th }}$, 1998.

A rthur, W. B. (1988), 'Competing technologies: an overview', in D osi, $G$. et al (eds), Technical Change and E conomic Theory. Francis Pinter.

A verstad, K. (1998), Interview with K enneth A verstad, V attenfall M iljöE I. O ctober 22 $2^{\text {nd }}, 1998$.

B ijker, W . E . (ed.) (1995), O f B icycles, B akelites, and Bulbs: Toward a Theory of Sociotechnical Change, The M IT Press. Cambridge, $M$ assachusetts.

BTM (eds) (1999), World M arket U pdate 1998, BTM Consult A pS. R ingkobing, D enmark. 
Carlman, I. (1990), 'B låsningen: Svensk vindkraft 1973 till 1990'.

G eografiska R egionstudier $\mathrm{N} \mathrm{r}$ 23, K ulturgeografiska institutionen vid U ppsala universitet. (In Swedish)

Carlsson, B . (ed.) (1995), Technological Systems and E conomic Performance: The $\mathrm{C}$ ase of F actory A utomation, K luwer A cademic Publishers. D ordrecht.

Carlsson, B . (ed.) (1997), Technological Systems and Industrial D ynamics, K luwer A cademic Publishers. N orwell, M assachusetts.

Carlsson, B . and J acobsson, S. (1997a), 'D iversity Creation and Technological Systems: A Technology Policy Perspective', in E dquist, C. (ed.), Systems of Innovation: Technologies, Institutions and O rganizations, Pinter Publishers, L ondon, 1997.

Carlsson, B. and J acobsson, S. (1997b), 'In Search of U seful Public Policies: K ey Lessons and Issues for Policy M akers', in Carlsson, B . (ed.), Technological Systems and Industrial D ynamics, K luwer A cademic Publishers, N orwell, M assachusetts, 1997.

Carlsson, B . and Stankiewicz, R . (1991), 'O n the nature, function and composition of technological systems', J ournal of E volutionary E conomics. 2 (1), 93-118.

D osi, G . (1988), 'Sources, Procedures and M icroeconomic E ffects of Innovation', J ournal of E conomic L iterature, 26 (3), 1120-1171.

D osi, G . et al (eds) (1990), The E conomics of Technical Change and International Trade, $\mathrm{H}$ arvester/W heatsheaf, $\mathrm{N}$ ew $\mathrm{Y}$ ork.

E dquist, C. and J ohnson, B . (1997), 'Institutions and O rganizations in Systems of Innovation', in: E dquist, C. (ed.), Systems of I nnovation: Technologies, Institutions and O rganizations, Pinter Publishers, London, 1997.

E SIF (1996), Sun in A ction: The solar thermal market, E uropean Solar Industry Federation, $A$ thens.

E uropean Commission (1997), White Paper on Renewable E nergies CO M 97-599 final.

Fransman, M . (1990), The M arket and B eyond, Cambridge U niversity Press, Cambridge. 
Freeman, C. (1987), Technology Policy and E conomic Performance, Pinter Publishers $L \mathrm{td}$, London.

H ughes, T. P. (1983), N etworks of P ower: E lectrification in Western Society, 1880-1930, The J ohns H opkins U niversity Press, B altimore.

H åkansson, H . (ed.) (1987), Industrial T echnological D evelopment: A N etwork A pproach, Croom H elm, B echenham.

IEA (1998), Solar Energy A ctivities in IEA Countries 1997, $O E C D / I E A$.

IV A (1992), 'E nergi för kommande generationer: E nergiforskning 1975-1992', IV A -M 277, Ingenjörsvetenskapsakademien, Stockholm. J ohnson, A . (1998), Functions in Innovation System A pproaches, $M$ imeo, D epartment of Industrial D ynamics, Chalmers U niversity of Technology, G öteborg.

J ohnson, A . and J acobsson, S. (1999), 'Inducement and Blocking $M$ echanisms in the D evelopment of a $\mathrm{N}$ ew Industry: The Case of R enewable E nergy Technology in Sweden', in J ohnson, A . (ed.), (1999), Renewable E nergy Technology: A N ew Swedish G rowth Industry?, Thesis for the degree of licentiate of engineering, $D$ epartment of I ndustrial $D$ ynamics, Chalmers $U$ niversity of Technology, G öteborg.

K aramömerlioglu, D . and J acobsson, S. (2000), 'The Swedish venture capital industry - an infant, adolescent or grown-up?', V enture Capital, 2 (1), 61-88.

K line, S. and R osenberg, N. (1986), 'A n O verview of Innovation', in L andau, R. and R osenberg, N. (eds), The Positive Sum Strategy: $H$ arnessing Technology for E onomic G rowth, N ational A cademy Press, Washington D.C., 1986.

L undgren, A . (1991), Technological Innovation and Industrial E volution - the E mergence of I ndustrial N etworks, D octoral Dissertation, The E conomic R esearch Institute/Stockholm School of E conomics, Stockholm.

L undgren, A . and N ordenlöw, L. (1995), 'M ellan teknik och marknad tekniskt entreprenörskap i industriella nätverk', in Företag och marknader i förändring - dynamik i nätverk, Nerenius och Santéren Förlag, Stockholm, 1995. 
L undvall, B .-Å . (1992), 'N ational Systems of Innovation', in Lundvall, B.-Å. (ed.), National Systems of Innovation - toward a Theory of Innovation and Interactive $L$ earning, Pinter Publishers, L ondon.

M angold, D . (1999), 'J ährlich verkaufte K ollektorfläche in D eutschland', ITW U niversität, Stuttgart.

M askell. P. (1997), 'L ow-Tech L earning in the F urniture Industry', in E skelinen, $H$., (ed.), R egional Specialisation and L ocal E nvironment learning and competitiveness, N ordR efo, 1993:3, Stockholm, 1997.

M etcalfe, J . S. (1992), 'The E conomic F oundations of Technology Policy: E quilibrium and E volutionary Perspectives', (M imeo), $U$ niversity of $M$ anchester, $M$ anchester.

Nelson, R . R . (1992), 'National Innovation Systems: A R etrospective on a Study', Industrial and Corporate Change, no. 2, 347-374.

O hlsson, L. (1991), Förnyelsepolitiken och riskkapitalet. Industriförbundets förlag, Stockholm.

Porter, M . (1990), 'The Competitive A dvantage of Nations', H arvard Business R eview, M arch-A pril.

Porter, M . (1998), 'Clusters and Competition: N ew A gendas for Companies, G overnments, and Institutions', in: Porter, M . (ed.), On Competition, A H arvard B usiness R eview B ook, B oston.

Saxenian, A . L . (1994), Regional A dvantage. Culture and Competition in Silicon Valley and Route 128, $\mathrm{H}$ arvard U niversity Press, Cambridge, $M$ assachusetts.

SOU (1992), 'Biobränslen för framtiden'. (Final report of the Swedish biofuel commission), SO U 1992:90, J ordbruksdepartementet, Stockholm.

STE M (1998), E nergy in Sweden: Facts and Figures 1998, Swedish $N$ ational E nergy A dministration, Stockholm.

Weiss, W . (1999), 'The A ustrian Solar M arket', U R L: http://www.datenwerk.at/arge_ee/verz/english/market01.html (A cc. 2000-01-17). 